\title{
Formalização e Validação de Padrões para Apoiar o Design de Sistemas Educacionais com Coautoria
}

\author{
Formalization and Validation of Patterns to Support Designing Educational Systems \\ with Co-authorship
}

\author{
Marcos Alexandre Rose Silva \\ Colégio Politécnico \\ Universidade Federal de Santa Maria (UFSM) \\ marcos.silva@ufsm.br
}

\author{
Junia Coutinho Anacleto \\ Departamento de Computação \\ Universidade Federal de São Carlos (UFSCar) \\ junia@dc.ufscar.br
}

\begin{abstract}
Resumo A adequação no conteúdo educacional de acordo com a cultura, o conhecimento e valores dos alunos permite aos mesmos identificarem relação entre o que estão aprendendo e suas realidades e, consequentemente se sentirem mais interessados e engajados no aprendizado. Contudo, no contexto da informática na educação, fazer o design de sistemas educacionais para permitir a adequação é um desafio, tanto pela falta de técnicas para apoiar o design, quanto pela dificuldade em identificar o que adequar, como permitir e facilitar essa adequação, pois muitos dos usuários desses sistemas, como educadores e alunos, não têm conhecimento e experiência com design, fazendo com que essa tarefa seja complexa. Neste contexto, este artigo apresenta conceitos relacionados com a adequação de sistemas, que podem ser utilizados na área educacional, enfatizando a coautoria como a possibilidade de permitir aos usuários terem apoio para perceberem e inserirem as informações que serão exibidas nos sistemas. Para apoiar o design, este artigo descreve a formalização de nove padrões com soluções de sucesso para problemas recorrentes no design de sistemas educacionais que permitam coautoria e, para ilustrar como aplicá-los, há a descrição de um estudo de caso mostrando evidências de que esses padrões apoiam o design de forma que a coautoria seja percebida e utilizada.
\end{abstract}

Palavras-Chave: Coautoria; Educação; Sistema Educacional; Padrões; Design

\begin{abstract}
The adequacy of educational content considering student's culture, knowledge and values allows them to identify the relationship between what they are learning and their reality and, consequently they feel more interested and engaged at education. In contrast, in informatics at education, designing educational systems to allow adequacy is a challenge because of a lack of techniques to support it and it is difficult to identify what and how allow this adequacy in order to users of these systems can do that, because many users, as educators and students do not have knowledge of designing, making the adequacy a complex task. In this context, this paper presents concepts related to adequacy of systems that can be used at educational area, emphasizing co-authorship as the possibility to allow users identify and insert information to be displayed at systems. To support designing, this paper describes the formalization process of nine design patterns with successful solutions for recurrent problems on designing educational system that allows co-authorship and, in order to illustrate how to apply them, a case study is described showing evidences that these patterns support the design in a way that this co-authorship can be realized and used.
\end{abstract}

Keywords: Co-authorship; Education; Educational System; Patterns; Design 


\section{Introdução}

Segundo a National Academy of Engineering [50], comissão dos principais pensadores técnicos da Fundação Nacional de Ciência dos Estados Unidos, um dos 14 desafios do século 21 é o avanço nas pesquisas relacionadas à contextualização no processo de aprendizado, isto é, que o conteúdo didático e as demais informações sejam adequados às necessidades e características dos estudantes. A importância da contextualização também tem despertado o interesse de pesquisadores na área da computação. Inclusive, a Sociedade Brasileira da Computação (SBC) e a Sociedade de Interação Humano-Computador definiram desafios que estão diretamente relacionados com a importância de considerar o contexto. Os desafios são: Acesso participativo e universal do cidadão brasileiro ao conhecimento e; Acessibilidade e Inclusão Digital, respectivamente [1][46].

Esses desafios vão ao encontro de estudos de pesquisadores na área da educação, como Piaget [34] que relata a importância de considerar o contexto (a dificuldade, a cultura, a criatividade e o conhecimento) do aluno nas atividades e ferramentas utilizadas em sala de aula, pois ao identificar relação entre o que está aprendendo e a sua realidade, o aluno se sente mais interessado e engajado.

Contudo, fazer o design de sistemas que possam ser adequados é um desafio, principalmente porque ao visualizar as interfaces do sistema, os usuários precisam perceber e entender como a contextualização pode ser feita [61][50]. Embora haja na literatura a discussão de conceitos que permitam adequação de sistemas computacionais, faltam técnicas, métodos para apoiar o design desses sistemas, por isso, há a necessidade de formalizar conhecimentos, métodos, frameworks e/ou estratégias [66][61][21].

Nesse contexto, a pergunta de pesquisa abordada nesse artigo é: Como apoiar o design de sistemas educacionais que possam ser contextualizados? A proposta e hipótese descrita, neste artigo, é que o conhecimento e experiência no design de sistemas educacionais que permitem coautoria, formalizados em padrões, apoiam o design de sistemas que podem ser adequados.

Para melhor compreensão da proposta, esse artigo está organizado da seguinte maneira: Seção 2 apresenta alguns conceitos que relatam a possibilidade de adequar sistemas computacionais, incluindo a coautoria; Seção 3 descreve o que são padrões de design e alguns exemplos; Seção 4 aborda o processo para formalizar padrões de design e apresenta o processo para formalizar os padrões de coautoria; na Seção 5 há a descrição dos padrões de coautoria e; em seguida são apresentadas as considerações finais.

\section{Adequação de Sistemas}

Existem conceitos que relatam formas de possibilitar a adequação dos sistemas computacionais considerando as características, necessidades e objetivos dos usuários. Neste artigo, alguns desses conceitos são apresentados em duas categorias: na primeira, ilustrada na Figura 1, os conceitos partem do princípio que já existe um sistema computacional e há possibilidade de adaptar ou inserir novas características e/ou funcionalidades; na segunda, ilustrada na Figura 2, os conceitos estão relacionados com a possibilidade de apoiar a criação de sistemas computacionais.

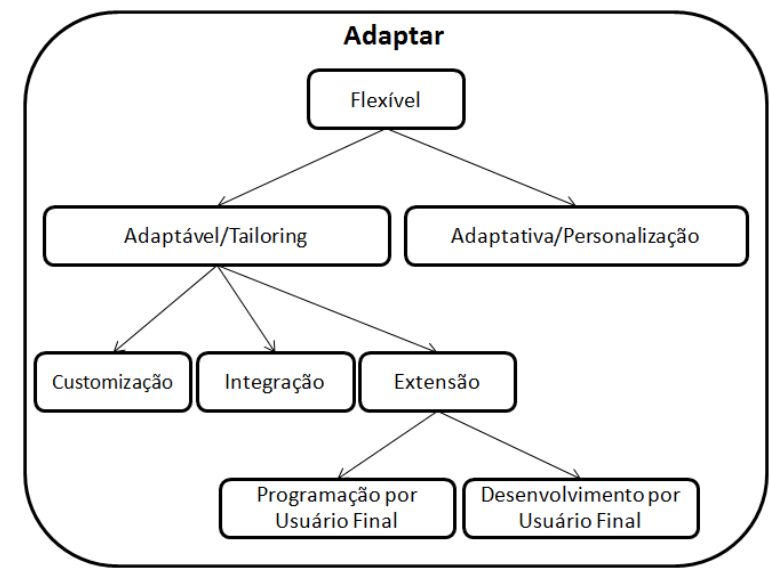

Figura 1: Conceitos relacionados à adaptação de sistemas

$\mathrm{Na}$ primeira categoria, os sistemas computacionais são considerados flexíveis, pois permitem o ajuste de suas configurações e funcionalidades [24]. É válido mencionar que nesta categoria os usuários já têm acesso ao sistema e, antes ou durante o uso do mesmo, as adaptações podem ser feitas. Por exemplo, no sistema Yahoo, Yahoo.com, o usuário pode acessar e navegar sem fazer qualquer alteração inicial e, durante o uso pode fazer edições no sistema para adaptá-lo de acordo com suas preferências, como também há a possibilidade de editá-lo logo no início.

Nos sistemas flexíveis as adaptações podem: (1) ser feitas automaticamente, considerando modelos de comportamento [21], modelos de decisão, entre outras estratégias que permitem aos sistemas identificarem características dos usuários e se adequarem de acordo; neste caso, são considerados sistemas adaptativos ou personalizáveis [26][53]; ou (2) partir explicitamente dos usuários, neste caso são considerados sistemas adaptáveis ou tailoring [56].

O pesquisador Morch [7] propôs três níveis de tailoring: customização, integração e extensão. A principal diferença, entre os níveis, está no esforço que o usuário tem para adaptar o sistema, pois ele pode desde selecio- 
nar até programar o que deseja adaptar.

$\mathrm{Na}$ customização, os usuários podem fazer adaptações considerando um conjunto pré-definidos de opções de configurações e funcionalidade e/ou alterando os parâmetros dos objetos existentes na interface. $\mathrm{Na}$ integração, há a possibilidade de alterar os sistemas além da seleção das opções pré-definidas. Neste nível é possível inserir um novo conteúdo, inserir imagens, gravar sequência de execuções como macros, agregar funcionalidades de outros sistemas, etc.

Há modelos como Modelo de processo para flexibilização de interface [16], frameworks como PLuRal [66]; entre outras técnicas como The Buzz [36] que apoiam o desenvolvimento de sistemas que permitem customização e integração.

Na extensão, os usuários têm a possibilidade de codificar/programar as adaptações. Neste contexto, há os conceitos de Programação por Usuários Finais e Desenvolvimento por Usuários Finais que têm como enfoque permitir e principalmente facilitar aos usuários, programadores ou não, codificarem o que precisa ser alterado [24][3][37][7].

Segundo Morch [7] a programação pelo usuário final permite aos usuários modificarem partes do sistema, ou construírem pequenos programas para integrar no sistema; enquanto o desenvolvimento pelo usuário final, segundo Rode [37], permite ao usuário modificar qualquer parte do sistema, podendo inclusive desenvolver um novo sistema. Meta-Design é uma estratégia que apoia o desenvolvimento desses tipos de sistema [24].

É válido mencionar que outros pesquisadores investigam um ou mais desses conceitos apresentados, inclusive nomeando-os diferente, por exemplo Trigg et al., [54] citam parametrização ao invés de customização; entre outros pesquisadores que investigam a flexibilidade [42][2][9].

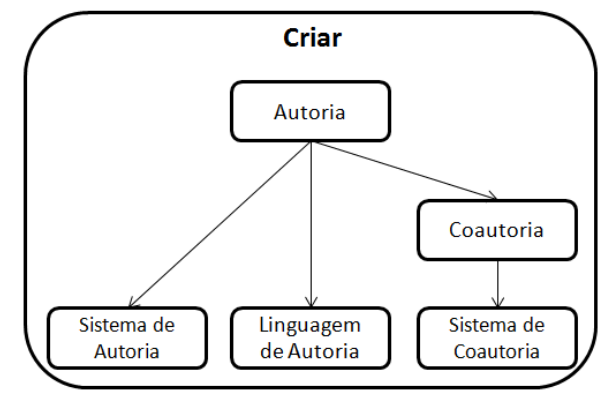

Figura 2: Conceitos relacionados à criação de sistemas

$\mathrm{Na}$ segunda categoria, os sistemas computacionais de autoria permitem ao usuário leigo ou programador, como autor, criar um sistema para ser usado por outros usuários [67][43]. Bez [47] descreve alguns sistemas de autoria em que o autor tem a possibilidade de criar por meio de um Sistema de Autoria [18]; ou programando por meio da Linguagem de autoria [15], o sistema que vai aparecer para o usuário, definindo em que local, cor, tamanho e fonte as informações vão aparecer; quais serão as regras de navegação, no caso de um Web site ou qual é o tempo, lógica, etc. em caso de jogos; etc.. Um exemplo de sistema e linguagem de autoria é o CMacromedia Flash, pois permite criar desde animações até aplicações computacionais por drag and drop ou programação.

Ressalta-se que a diferença entre a primeira e a segunda categoria é que em sistema que permite adaptação, o usuário já tem acesso ao produto/sistema final com informações, opções, etc., e pode ou não adaptá-las; enquanto no sistema de autoria, o usuário tem acesso a um sistema em que é necessário criar o produto final, inserindo informações e/ou opções, etc. Neste ultimo caso, o usuário é responsável por se preocupar com todas as características que serão apresentadas para outros usuários.

\subsection{Coautoria}

A coautoria, assim como a autoria, tem como objetivo apoiar o desenvolvimento de um sistema que permite a criação de produto/sistema final; entretanto, essa autoria ou a preocupação com todas as características, descritas acima, é compartilhada.

Na coautoria há três perfil de pessoas: autor, coautor e usuário final. Autor representa todas as pessoas envolvidas com o design do sistema de coautoria, podendo incluir profissionais da computação; artes; no contexto educacional, diretores, professores, alunos, entre outros. Coautor representa os usuários que vão utilizar o sistema de coautoria para inserir o conteúdo, que são as informações de acordo com as características e necessidades dos usuários finais, ou seja, o coautor é responsável por criar instâncias do sistema de coautoria inserindo as informações que serão exibidas nas mesmas. Usuário final representa os usuários que vão utilizar as instâncias.

É válido ressaltar que uma mesma pessoa pode ter os três perfis. Por exemplo, no contexto educacional, um aluno pode participar da equipe de design de um sistema de coautoria, auxiliando com ideias, falando do que gosta ou não, etc. (autor); como também pode inserir as informações que vão ser exibidas em uma instância desse sistema de coautoria (coautor) para ela e seus amigos utilizarem (usuário final). Sendo assim, não existe um perfil fixo para uma determinada pessoa, a pessoa assume um perfil de acordo com o seu objetivo [6][44].

A Figura 3 representa um sistema educacional que permite coautoria. O sistema é um jogo semelhante ao quiz, em que o usuário final ao visualizar de 1 a 10 dicas tem que adivinhar a palavra secreta. Nesse sistema, o autor foi responsável por definir todo o layout do jogo, 
como as cores, em que local aparecem as dicas, o espaço para inserir a palavra secreta, etc. O coautor foi responsável por inserir dicas e palavra secreta. $\mathrm{O}$ usuário final utilizou o jogo para aprender/relembrar alguns conceitos ao tentar adivinhar qual seria a palavra secreta considerando as dicas.

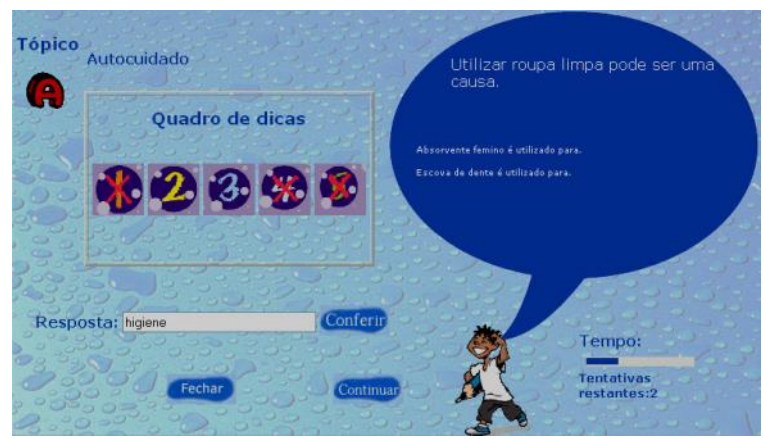

Figura 3: Jogo de Adivinhação [6]

Enfim, o autor é responsável por criar o sistema de coautoria, definindo: Figura 4 (I), as suas interfaces contendo cor, logotipo, instruções, opções, etc.; (II), quais e como as informações serão inseridas; (III), interface da instância. O coautor é responsável por acessar o sistema de coautoria (I) para inserir as informações (II) que serão exibidas nas instâncias (III). O Usuário final acessa o sistema de coautoria (I) para utilizar as instâncias (III). No sistema $\mathrm{O}$ que é, o que é? há duas opções em uma das telas iniciais, uma opção é "Criar Jogo" para o coautor inserir as informações e, a outra é "Jogar" para o usuário final acessar as instâncias.

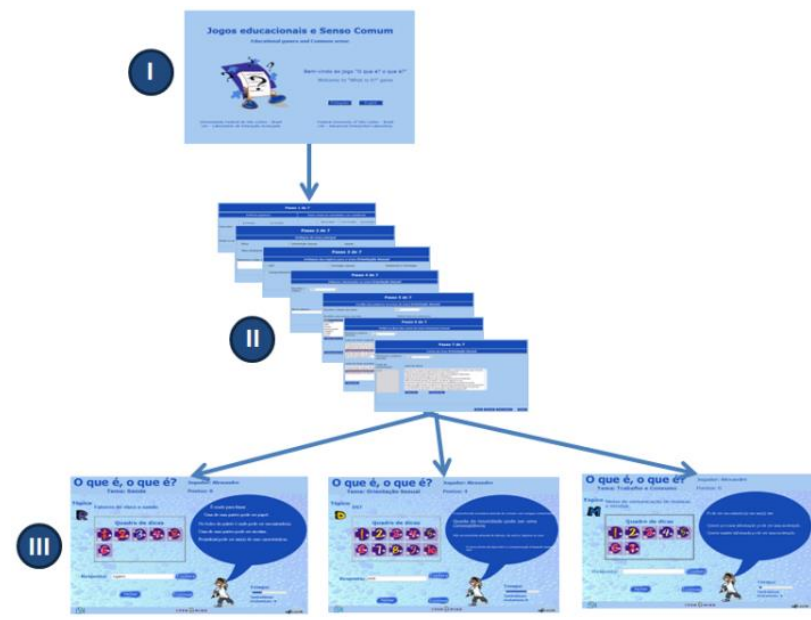

Figura 4: Exemplo de partes do sistema de coautoria

A coautoria tem sido uma estratégia útil, na área educacional, para permitir ao coautor utilizar um mesmo sistema em diferentes momentos, disciplinas, etc., bem como para oferecer ao mesmo a liberdade de inserir as informações de acordo com o seu princípio pedagógico, características e necessidades dos usuários finais. Afinal, um mesmo sistema, como o jogo quiz, pode ser interes- sante em muitas situações ou disciplinas, contudo, se as dicas e as palavras secretas fossem fixas, poderia limitar o seu uso para uma ou outra disciplina que estivessem relacionadas a essas informações pré-definidas. Caso o jogo fosse de autoria, o usuário poderia encontrar dificuldades em definir em que local as dicas, palavras secretas, entre outras características seriam exibidas e, essa tarefa poderia levar um tempo considerável, uma vez que nem sempre o usuário tem conhecimento e experiência com design de interfaces [6][44][31].

Existem pesquisas que investigam estratégias para apoiar o planejamento e desenvolvimento de sistemas, se preocupando com a informação que será exibida, como o Diagrama de Classe da Unified Modeling Language (UML) [5]; ontologias [8] e; modelos de tarefas ConcurTaskTrees [4]. Apesar dessas pesquisas não serem direcionadas para autoria e coautoria, há a possibilidade de mapear quais serão as informações de entrada e saída e, com base nesses dados observar quais informações podem ser inseridas pelo coautor. Entretanto, as estratégias não estão relacionadas em como fazer o design das interfaces do processo de coautoria, que é a forma que o coautor pode perceber a possibilidade de coautoria e inserir as informações. Nesse contexto, este artigo apresenta a formalização de padrões para apoiar o design das interfaces do processo de coautoria.

\section{Padrões de Design}

O conceito de padrões de design, ou em inglês Design Patterns, foi inspirado no trabalho do arquiteto e urbanista Alexander que teve como objetivo registrar a essência de solução de sucesso de problema recorrente em certo contexto [13][33]. Alexander começou a observar que em suas construções (projetos), e de seus pares, muitos dos problemas que ocorriam eram os mesmos. Considerando a sua experiência e observação em resolver tais problemas, Alexander percebeu que para cada problema havia uma estratégia adequada para solucioná-lo e, que sempre o resultado ao aplicar a estratégia era satisfatório [13].

Com essa experiência em resolver um problema recorrente com uma solução de sucesso, Alexander decidiu documentar essas informações para que ele pudesse relembrar da solução quando fosse necessário, compartilhar esse conhecimento e experiência com os demais colegas, bem como, facilitar a comunicação entre os membros de equipes interdisciplinares e com os clientes/usuários, pois as informações são apresentadas com uma linguagem simples e exemplos para apoiar a compreensão [13].

Segundo Michael et al., [32], o conceito de padrões surgiu na área da computação, em especial na Engenharia de Software (ES), por meio dos autores Kent Beck e Ward Cunningham ao escrevem um artigo sobre a aplicação de linguagem de padrões para desenvolver software 
orientado a objetos [40].

Em 1997, houve a primeira discussão sobre o uso de padrões na área da Interação Humano-Computador (IHC) em um workshop realizado pela conferencia Computer Human Interaction (CHI) [32]. A partir dessa discussão, pesquisadores na área de IHC iniciaram a formalização e escrita de padrões considerando a observação, experiência e conhecimento obtidos no design da interface.

No design, há padrões que descrevem soluções para problemas recorrentes em diferentes contextos. A Tabela 1 ilustra alguns exemplos existentes em IHC.

\begin{tabular}{l|l}
\hline Contextos & Padrões \\
\hline Web & $\begin{array}{l}\text { Montero et al., [22]; Duyne et al., } \\
{[17] ; \text { Yahoo! [67] }}\end{array}$ \\
\hline $\begin{array}{l}\text { Web e dispositivos } \\
\text { móveis }\end{array}$ & Welie [49] \\
\hline Interação social & Arvola [45]; Crumlish et al., [14] \\
\hline $\begin{array}{l}\text { Trabalho coopera- } \\
\text { tivo apoiado por } \\
\text { computador } \\
\text { (CSCW) }\end{array}$ & $\begin{array}{l}\text { Clear et al., [63]; CSEG [62]; } \\
\text { [10] }\end{array}$ \\
\hline $\begin{array}{l}\text { Computação ubí- } \\
\text { qua }\end{array}$ & Chung et al., [20]; Roth [38] \\
\hline $\begin{array}{l}\text { Jogos } \\
\text { Casas Digitais }\end{array}$ & Roth et al., [57] Wasson et al., \\
\hline $\begin{array}{l}\text { Sistemas para } \\
\text { feiras de exposição }\end{array}$ & Borches [28] \\
\hline $\begin{array}{l}\text { Gerais: design para } \\
\text { a interação huma- } \\
\text { no-computador e } \\
\text { humano-objetos }\end{array}$ & $\begin{array}{l}\text { Beck [41]; Coram et al., [64]; } \\
\text { Tidwell [39]; Laakso [59]; Löw- } \\
\text { gren [30]; UC Berkeley [11] }\end{array}$ \\
\hline
\end{tabular}

Tabela 1: Contextos e seus respectivos padrões

\section{Formalização de Padrões de Coau- toria}

De forma semelhante ao Alexander [13], os padrões de design têm sido formalizados considerando a experiência e a observação [52][51]. Experiência em se fazer o design de sistemas computacionais [55][25] e observar as soluções de sucesso encontradas [12][58].

Essas soluções podem ter sido observadas durante anos de experiência [65][33][20], por um período determinado para realizar alguns workshops [29], bem como por um período curto, por exemplo um mês [10].

Os padrões de coautoria, descritos neste artigo, representam observações, conhecimentos e experiências em 10 anos de pesquisas, no design e observação de sistemas educacionais que permitem coautoria, incluindo seis sistemas de coautoria feitos a partir da troca de experiências, reuniões, conversas formais e informais entre os pesquisadores dos laboratórios, que os autores deste arti- go trabalham, e outros profissionais como educadores, psicólogos, psicopedagogos, terapeutas, fisioterapeutas, entre outros; por isso, não há um registro formal de como foram feitos esses designs.

Os objetivos principais de formalizar esses padrões são: (1) registrar os problemas e/ou soluções específicos da coautoria, ou seja, problemas ou soluções que não foram encontrados nos outros padrões de design investigados e listados na Tabela 1; (2) auxiliar outros pesquisadores/profissionais a conhecerem e permitirem a coautoria em seus sistemas.

A Figura 5 representa os passos para a formalização dos padrões. Todos os passos foram percorridos em ciclos de forma iterativa. A seguir são apresentados brevemente cada passo e nas próximas subseções há a descrição de três ciclos feitos.

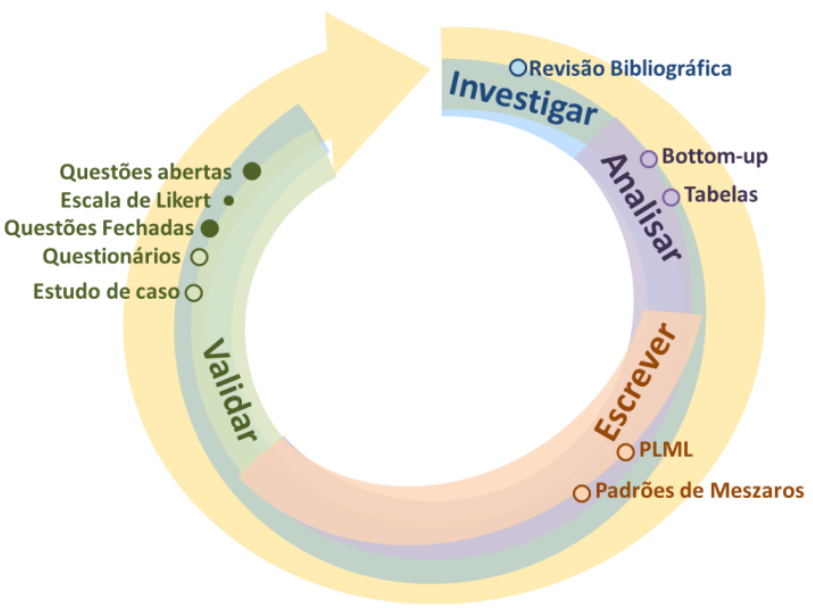

Figura 5: Passos para formalizar os padrões de coautoria

Investigar - passo que permeia todos os outros, pois há a Revisão Bibliográfica para investigar padrões de design, conceitos e pesquisas relacionadas a adequação e a coautoria; estratégias e metodologias para Analisar soluções de sucesso e Escrever os padrões; bem como técnicas e artefatos para Validar a compreensão e uso dos padrões.

Analisar - passo em que há a observação e a abstração das soluções de sucesso existentes nas interfaces de sistemas que permitem coautoria [6][44][31]. A análise é feita de forma Bottom-up, em que cada interface é analisada para se coletar as características do design, ou seja, o que e como é exibido [65][20]. A partir desses dados, são feitas comparações para identificar quais as características comuns entre todos os sistemas. Essas características são consideradas as soluções de sucesso, pois elas se repetiram em todos os sistemas durante os anos de pesquisas e experimentos feitos para se observar a viabilidade dos mesmos

As interfaces contendo as características comuns fo- 
ram organizadas utilizando a estratégia de Tabelas descrita por Finlay [29]. Cada tabela está relacionada a um problema e, contém as interfaces dos sistemas que ilustram as soluções de sucesso, como ilustrado na Tabela 2. Os problemas são abstraídos a partir das soluções. Por exemplo, todos os sistemas possuem na interface inicial um botão para ilustrar a opção de coautoria. A necessidade de o botão estar na interface inicial e o que está escrito nele é para evitar o problema do coautor não identificar a opção de coautoria.

Problema: Como o coautor pode saber desde o início que há a opção de coautoria?

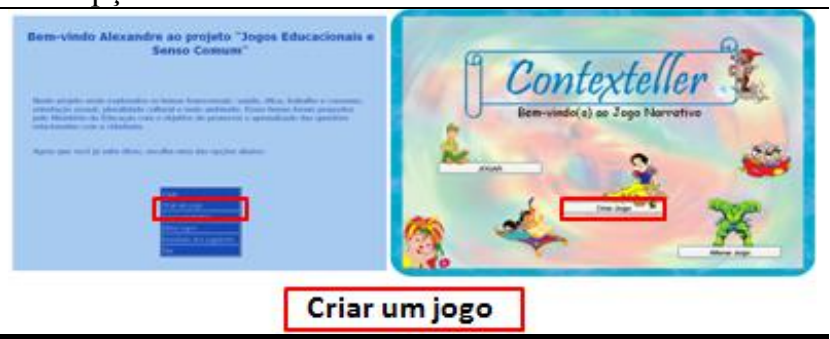

Tabela 2: Duas interfaces que ilustram uma solução de sucesso

Escrever - passo que registra o que foi obtido nos passos anteriores por meio de padrões. Os padrões foram escritos com base em padrões de Meszaros e PLML (Pattern Language Markup Language), que representam padrões e estruturas que descrevem como formalizar padrões, incluindo quais são as informações obrigatórias e optativas para expor os conhecimentos e experiências [25][23].

Os padrões de coautoria contêm todas as 5 informações obrigatórias e 2 opcionais, que são: Nome do Padrão: Informa a ideia principal do padrão; Problema: Contém o problema específico que o padrão se propõe a resolver; Contexto: Caracteriza situações em que o problema pode acontecer e que o padrão pode ser aplicado com sucesso; Forças: São considerações que requerem solução; Solução: É a mensagem principal do padrão, pois apresenta a proposta de solução para o problema; Raciocínio: descrição além da solução, fornecendo os processos de pensamento por trás da escolha da solução; Exemplo: a solução pode ou não estar acompanhada por ilustrações para facilitar o entendimento.

Validar - passo que há a leitura e/ou uso dos padrões. Em cada validação há questionários para coletar dificuldades e facilidades em compreender os padrões; relatar sobre a existência ou não das soluções de sucessos nos sistemas observados; bem como as vantagens e desvantagens de fazer o design de interfaces utilizando os padrões e; utilizar essas interfaces para inserir as informações que serão exibidas no sistema.

A maior parte dos questionários foi feita considerando a escala de Likert, em que é possível avaliar a satisfação das pessoas por meio de graus de satisfação que variam de um grau mais alto para um grau mais baixo, como "Concordo Fortemente", "Concordo", "Indiferente", "Discordo" e "Discordo Fortemente" [35]; também houve questões abertas e outros tipos de questionários que serão discutidos no decorrer deste artigo.

\subsection{Primeiro Ciclo}

No primeiro ciclo houve a formalização de seis padrões: "Processo de coautoria" para apresentar o que é coautoria e descrever as principais características, que são explicadas com mais detalhes nos outros padrões; que são a exibição da "Opção de coautoria" para haver a possibilidade de percepção dessa opção e, consecutivamente o uso, ilustrado na Figura 6; divisão de "Passos" para explicar e conduzir a inserção das informações; explicando "O que precisa ser feito" em cada passo; bem como permitir o "Reuso do conteúdo"; exibindo as "Informações existentes" antes e/ou durante a inserção das informações para que o coautor possa utilizar quaisquer informações inseridas por ele ou por outros. Ressalta-se que as palavras entre aspas são os nomes dos padrões.

Nome: Opção de coautoria

Contexto: $\mathrm{O}$ coautor precisa perceber que há a possibilidade de inserir as informações que serão exibidas no sistema.

Problema: Como o coautor pode saber desde o início que há opção de coautoria?

Forças: Se não existe a coautoria, não existem as informações do sistema; o coautor não utiliza a opção de coautoria se não identificá-la.

Solução: Deixe visível a opção para a coautoria no início da interação; exiba o nome da opção utilizando algum verbo no infinito que expresse a ação de coautoria, como "criar"; em seguida pode ser exibido o que será criado, como "jogo".

Raciocínio: Um dos principais problemas que faz com que o coautor não utilize a opção de coautoria é devido à não percepção dessa opção. Por isso, é necessário indicar de forma clara que existe a opção de coautoria no sistema.

\section{Exemplo:}

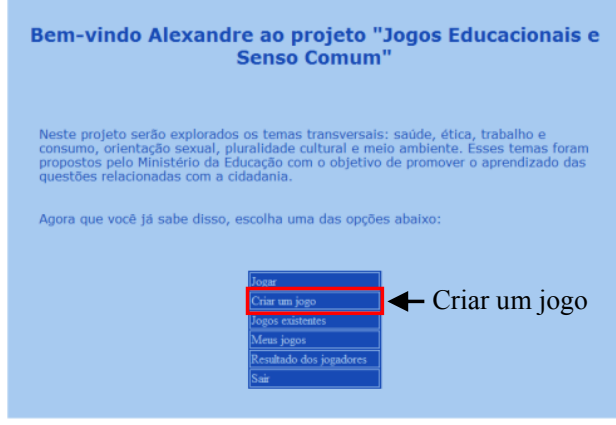

Figura 6: Versão inicial do padrão "Opção de Coautoria" 
É válido mencionar que durante a observação e escrita, houve a preocupação em formalizar os conhecimentos e experiências específicos de coautoria, não mencionados nos padrões investigados. Por exemplo, apontar como solução de sucesso a divisão em passos foi descrito por Tidwell [39] em seu padrão "Step by step instructions", Welie [49] em "Wizard" e Duyne [17] em "Process Funnel".

Entretanto, o "Passos", descrito neste artigo, relata sobre a importância de dividir os passos considerando as informações a serem inseridas e não as tarefas como os outros; reforça também a possibilidade de permitir ao coautor a liberdade de cancelar, voltar ou avançar nos passos conforme desejar, algo não descrito por Duyne e o oposto do que relata Welie, em que há a necessidade de preencher um passo para ir ao próximo. No "Passos" também se encontra exemplos específicos de sistemas que permitem coautoria.

Apesar de definir uma sequência de passos inicial, permitir voltar ou avançar nos passos oferece ao coautor a liberdade de decidir a ordem que ele se sente mais confortável para preencher. Por exemplo, no estudo de caso feito com um jogo narrativo, que permite coautoria, em que há inserção das informações sobre o tema da história após a inserção dos nomes e características dos personagens, observou-se que alguns coautores preferiram inserir o tema antes e outros não [44]. Ressalta-se que mesmo com essa liberdade é necessário inserir todas as informações obrigatórias para concluir o processo de coautoria.

Os seis padrões foram avaliados por cinco estudantes que tinham iniciado suas atividades recentemente no Laboratório de Interação Avançada (LIA) da UFSCar e, por isso, não conheciam os sistemas de coautoria e suas características. Quatro estudantes de mestrado e já conheciam o conceito de padrões, dois desses têm experiência em utilizar padrões no design e, um estudante estava na iniciação científica e não conhecia o conceito de padrões.

O objetivo foi avaliar a compreensão dos estudantes ao ler os padrões. Segundo Meszaros [25] é importante ter pessoas para lerem e avaliarem os padrões durante a formalização, pois cada pessoa possui diferentes conhecimentos, interpretações, etc., que podem ajudar a identificar e melhorar o que está sendo transmitido pelos padrões.

Nessa validação, os estudantes leram os padrões para analisar o que e como está escrito, se os exemplos ilustram o que está na solução e, se os padrões descrevem de forma clara o seu objetivo. O objetivo foi escrito, em uma frase, antes de cada padrão, por exemplo, antes do padrão "Opção de Coautoria" havia o objetivo - "Fazer as pessoas pensarem na opção de coautoria e em como ela deve ser exibida". A Tabela 3 ilustra parte do resultado do questionário.

\begin{tabular}{l|l}
\hline Questões & Respostas dos estudantes \\
\hline $\begin{array}{l}\text { Fácil compreender } \\
\text { os padrões }\end{array}$ & $\begin{array}{l}1 \text { concorda fortemente; } 4 \text { concor- } \\
\text { dam. }\end{array}$ \\
\hline $\begin{array}{l}\text { Os padrões descre- } \\
\text { vem de forma clara } \\
\text { seus objetivos. }\end{array}$ & $\begin{array}{l}4 \text { concordam fortemente; } 1 \text { con- } \\
\text { corda. }\end{array}$ \\
\hline $\begin{array}{l}\text { As imagens dos } \\
\text { exemplos ilustram } \\
\text { adequadamente as } \\
\text { soluções dos pa- } \\
\text { drões. }\end{array}$ & $\begin{array}{l}1 \text { concorda; } 1 \text { indiferente; } 3 \text { dis- } \\
\text { cordam. }\end{array}$ \\
\hline
\end{tabular}

Tabela 3: Parte do questionário sobre a leitura dos padrões

No questionário, todos os estudantes concordaram que foi fácil compreender os padrões e que os mesmos descreviam de forma clara seus objetivos. Alguns comentários foram que "os exemplos facilitam o entendimento", "padrões estão escritos de maneira clara e sucinta". Contudo, segundo a maioria dos estudantes, os exemplos poderiam ser melhor apresentados para ilustrar de forma adequada as soluções. Alguns comentários foram " $p a$ dronizar as indicações feitas nas imagens, ora estão por setas, ora estão como retângulos vermelhos"; "todas as imagens deveriam ter partes destacadas, como os padrões "Passos" e "Opção de coautoria"'; "Não consegui compreender o exemplo do processo de coautoria... Por que há "balõezinhos" com explicações no exemplo?"; "Seria interessante ter um breve cenário exemplificando as imagens. Uma vez que as interfaces possuem muitos detalhes".

\subsection{Segundo Ciclo}

Considerando a validação do ciclo anterior, o padrão "Processo de coautoria" foi reescrito, pois como ele apresenta o processo e suas características havia interfaces com muitas características e, os balões continham a explicação do porque de cada uma.

Após a validação percebeu-se o excesso de informação em cada exemplo, por tanto, os exemplos de todos os padrões foram alterados para que a parte da interface que ilustra a solução fosse destacada. No "Processo de coautoria" foi reduzida a quantidade de características ilustradas. As características foram destacadas com a sua respectiva explicação.

Nesse ciclo, os padrões foram avaliados por seis pesquisadores que acompanharam e/ou desenvolveram pelo menos um dos seis sistemas que permitem coautoria. Cada padrão foi enviado para apenas um pesquisador.

O objetivo foi avaliar se o pesquisador identificava a solução descrita no padrão no sistema que desenvolveu; se cada padrão é compreensível e autocontido; bem como, instigar os pesquisadores, ao lerem um padrão, descreverem outras características que consideram importantes para um sistema que permita coautoria. Essas caracte- 
rísticas seriam comparadas com os outros padrões formalizados para verificar se as mesmas foram descritas ou não. A Tabela 4 ilustra parte do resultado do questionário enviado junto com os padrões.

\begin{tabular}{l|l}
\hline Questões & $\begin{array}{l}\text { Respostas dos Parti- } \\
\text { cipantes }\end{array}$ \\
\hline Fácil compreender os padrões & $\begin{array}{l}2 \text { concordam fortemen- } \\
\text { te; } 4 \text { concordam. }\end{array}$ \\
\hline $\begin{array}{l}\text { As imagens dos exemplos } \\
\text { ilustram adequadamente as } \\
\text { soluções dos padrões. }\end{array}$ & $\begin{array}{l}1 \text { concorda fortemente; } \\
5 \text { concordam. }\end{array}$ \\
\hline $\begin{array}{l}\text { O padrão se aplica aos siste- } \\
\text { mas de coautoria que desen- } \\
\text { volveu e/ou que acompanhou } \\
\text { o desenvolvimento. }\end{array}$ & $\begin{array}{l}2 \text { concordam fortemen- } \\
\text { te; } 4 \text { concordam. }\end{array}$ \\
\hline
\end{tabular}

Tabela 4: Parte do questionário sobre a comparação dos padrões com os sistemas que permitem coautoria

No questionário, todos os pesquisadores concordaram que foi fácil compreender os padrões; que as imagens ilustram adequadamente as soluções e; os padrões se aplicam aos sistemas de coautoria que eles desenvolveram. Alguns comentários sobre os padrões foram: com relação ao exemplo do padrão "Passos" - pode ser interessante "mostrar um esquema em protótipo com os passos e depois os passos (de forma completa) de um dos sistemas"; para o padrão "Informações existentes" "característica relacionada com que o coautor possa reusar as informações de outros coautores acredito que é essencial"; para o padrão "Processo de coautoria" - "abstrato e genérico. O próprio nome é genérico. Um padrão que se chama processo? Precisa ser mais específico. Há a possibilidade de dividir esse padrão em vários?".

Com relação a pergunta do questionário "Você teria alguma informação ou sugestão a uma pessoa que deseja desenvolver um sistema que permita coautoria?". Todas as sugestões descritas já estavam relacionadas com um dos padrões, por exemplo, para a sugestão "processo de coautoria deve ser simples, além disso no passo a passo" - há o padrão "Passos"; "possibilitar desfazer qualquer ação" - padrão "Característica dos passos"; "deve ser provida informações para esclarecer o que deve ser feito" - padrão "O que precisa ser feito". Ressalta-se que essas sugestões foram feitas por pesquisadores que não avaliaram os padrões relacionados, por exemplo, o pesquisador que sugeriu "processo de coautoria deve ser simples, além disso no passo a passo" não tinha lido o padrão "Passos".

\subsection{Terceiro Ciclo}

Considerando todo o resultado da validação do ciclo anterior, os padrões encontrados na literatura foram investigados novamente com o objetivo de compará-los com o resultado. Com relação ao comentário sobre mos- trar, no exemplo, um esquema e depois a interface do sistema foi uma estratégia feita por alguns autores como Tidwell [39] em que há um esquema e/ou fluxograma para explicar a lógica e, em seguida há a interface.

Outros autores como Welie [49] e Montero [22] ilustram apenas a parte da interface que exemplifica o que está descrito na solução, ou seja, não exibem a interface completa com destaque em uma parte. Essa foi a estratégia adotada nos padrões de coautoria, para tanto os exemplos foram modificados para conterem apenas a parte que ilustra a solução. A adoção dessa estratégia foi para observar se o enfoque apenas na solução ajudaria na compreensão dos exemplos; contudo, outra validação seria feita para observar se essa estratégia é o suficiente ou se é necessário ilustrar também um esquema/fluxograma.

Ao investigar outros padrões também se observou que na descrição da solução não há exemplificação, como feito em alguns padrões de coautoria. A Figura 6 ilustra um padrão em que na solução há a descrição de como a opção de coautoria deveria ser descrita. Entretanto, as soluções devem conter apenas a essência da solução, sem instanciá-la. A instância da solução deve estar nos exemplos [25]. Todos os padrões de coautoria que tinham essa característica foram modificados.

Com relação ao padrão "Processo de coautoria" confirmou-se que ele é abstrato e genérico, o que dificulta a sua compreensão. Nos padrões identificados na literatura, não há um padrão para explicar de forma geral todas as características, mas sim cada padrão explica uma característica e, a junção de todos os padrões se alcança o todo. Essa estratégia foi adotada, o padrão "Processo de coautoria" foi excluído e manteve-se apenas os outros padrões que explicam uma característica. Dessa forma, a junção de cada padrão específico se alcançaria o todo, ao invés de ter um padrão que apresentasse toda a ideia e característica de coautoria.

O padrão "Informações existentes" também foi alterado, pois nele havia explicações sobre o que são informações, no contexto de coautoria, que deveriam ser inseridas pelo coautor e, como reusá-las. Esse padrão, chamado agora "Informações", contém apenas explicações sobre o que são informações e, a parte do reuso foi descrito no padrão "Reuso do Conteúdo". Para exemplificar as modificações, a Figura 7 ilustra o padrão "Opção de coautoria" após as alterações.

Nome: Opção de coautoria

Contexto: O coautor precisa perceber que há a possibilidade de inserir as informações que serão exibidas no sistema.

Problema: Como o coautor pode saber desde o início que há opção de coautoria?

Forças: O coautor não utiliza a opção de coautoria se 
não identificá-la.

\section{Solução:}

Deixe visível a opção para a coautoria no início da interação, com uma frase indicativa.

Nessa frase há um verbo no infinito que expressa a ação de coautoria, seguido do que será feito.

Por meio da opção de coautoria, o coautor indica o desejo de inserir Informações que serão exibidas no sistema por meio de Passos.

Raciocínio:

Um dos principais problemas que faz o coautor não utilizar a opção de coautoria é a não percepção dessa opção.

Coautor é o usuário do sistema de coautoria responsável por inserir as informações que serão exibidas no mesmo.

Ao inserir informações, cada coautor tem a possibilidade de criar várias instâncias. Uma Instância significa o sistema de coautoria com as informações que um coautor inseriu. Por exemplo, um sistema de coautoria semelhante a um jogo Quiz, em que há uma palavra secreta que deve ser adivinhada considerando dicas, permite ao coautor criar instâncias com dicas e palavra secreta relacionadas ao meio ambiente, a biologia, entre outros temas assuntos.

Exemplos:

\section{Criar um jogo}

\section{Iniciar uma nova Ação de Aprendizagem}

Figura 7: Padrão "Opção de Coautoria" modificado

Durante os passos Observar e Escrever do processo de formalização dos padrões, Figura 5, também foi verificado que em todos os sistemas há a explicação do objetivo do sistema para permitir ao coautor identificar a finalidade do mesmo, por isso, formalizou-se o padrão "Objetivo". No total, nesse ciclo constam sete padrões "Opção de coautoria", "Objetivo", "Informações", "Passos", "Características dos passos", "O que precisa ser feito" e "Reuso do conteúdo".

Com o objetivo de observar o uso desses padrões foi feito um estudo para observar alunos, do ultimo ano de graduação em ciência e engenharia da computação, utilizando os padrões para fazer o design de protótipos de sistemas educacionais que permitam coautoria e; alunos da área de pedagogia e matemática utilizando esses protótipos para simular a coautoria.

No estudo participaram 22 alunos que fizeram uma disciplina optativa sobre conceitos de Interação HumanoComputador (IHC) no design de sistemas computacionais e, 4 alunos da graduação em pedagogia e matemática, que tiveram disponibilidade de participar do estudo no horário da disciplina. Quatro passos desse estudo de caso são descritos a seguir. Cada passo ocorreu em um dia da disciplina durante 2 horas.

\subsubsection{Primeiro Passo}

Os 22 alunos preencheram um pré-questionário considerando suas experiências e conhecimentos em Engenharia de Software (ES) e IHC. Esses alunos foram divididos em 5 grupos - 2 grupos com 5 alunos e 3 grupos com 4 alunos. Em cada grupo houve: 1 aluno com 18 meses de cursos em ES e que já desenvolveram sistemas, mas não conhecem os conceitos de IHC; 1 aluno com 12 meses de cursos em ES, mas não tem experiência com desenvolvimento de sistemas e nem conhecimentos sobre IHC; 1 aluno, ou 2 em grupos de 5, com 12 meses de cursos em ES e 6 meses de cursos em IHC com experiência prática em ambas áreas; 1 aluno com 6 meses de cursos em ES, mas não tem experiência com desenvolvimento de sistemas e nem conhecimentos sobre IHC.

Cada grupo fez um protótipo de um sistema educacional considerando os padrões e um cenário que pesquisadores, com experiência em desenvolver sistemas que permitem coautoria, escreveram enquanto estavam desenvolvendo um sistema para uma sala de alfabetização em uma escola pública, ou seja, no cenário há todas as informações utilizadas para planejar e, consecutivamente, desenhar as interfaces.

O cenário contém detalhes de como os professores da sala de alfabetização criam uma atividade, utilizando apenas papel, para apoiar a aprendizagem da leitura e escrita. A atividade, chamada Alfabeto Móvel, contém pedaços de papéis com uma letra do alfabeto em cada pedaço. Quando os professores querem ensinar uma palavra, por exemplo, LOBO, eles separam os pedaços de papéis que contem as letras para formar a palavra e, outros pedaços com diferentes letras para aumentar a complexidade da atividade. Os professores colocam esses pedaços de papéis embaralhados na mesa de cada aluno e o mesmo tem que reconhecer quais são as letras para formar a palavra.

\subsubsection{Segundo Passo}

Os 5 grupos leram os padrões e cenário para fazerem o design das interfaces do sistema educacional. Ressaltase que os alunos, em aulas anteriores, aprenderam sobre cenários e padrões de IHC, mas os conceitos foram explicados utilizando outros exemplos, ou seja, eles não conheciam a atividade Alfabeto Móvel e os padrões de coautoria. No final deste passo, cada aluno preencheu um questionário para relatar sobre dificuldades e facilidades em fazer o design de interfaces utilizando os padrões, como ilustrado na Tabela 5. Os questionários foram feitos considerando a escala de Likert [35]. 


\begin{tabular}{|c|c|}
\hline Questões & Respostas dos alunos \\
\hline $\begin{array}{l}\text { Fácil compreender } \\
\text { os padrões. Co- } \\
\text { mentários. }\end{array}$ & $\begin{array}{l}15 \text { concordam fortemente; } 7 \text { con- } \\
\text { cordam. "Eu levei alguns segun- } \\
\text { dos para observar a diferença } \\
\text { entre os padrões Passos e Carac- } \\
\text { terísticas dos passos, mas não é } \\
\text { dificil" }\end{array}$ \\
\hline $\begin{array}{l}\text { Facilidade / bene- } \\
\text { fício de utilizar os } \\
\text { padrões }\end{array}$ & $\begin{array}{l}22 \text { alunos escreveram respostas } \\
\text { como "Ajuda na elaboração das } \\
\text { ideias"; "A partir dos padrões foi } \\
\text { fácil fazer as interfaces". }\end{array}$ \\
\hline $\begin{array}{l}\text { Dificuldades / } \\
\text { desvantagens em } \\
\text { utilizar os padrões }\end{array}$ & Não mencionaram. \\
\hline
\end{tabular}

Tabela 5: Parte do questionário sobre o uso dos padrões

\subsubsection{Terceiro Passo}

Após o design das interfaces, cada grupo avaliou as interfaces de outros grupos considerando o método de inspeção de usabilidade baseado em padrões, que permite observar se o que está escrito nos padrões foi aplicado nas interfaces [48]. Parte do resultado da inspeção se encontra na tabela descrita a seguir.

\begin{tabular}{|c|c|c|}
\hline & $\begin{array}{l}\text { Padrões } \\
\text { aplicados }\end{array}$ & $\begin{array}{l}\text { Há todas as soluções descri- } \\
\text { tas em cada padrão? }\end{array}$ \\
\hline $\begin{array}{l}\text { Grupo } \\
\text { A }\end{array}$ & $\begin{array}{l}\text { Quase todos, } \\
\text { exceto os } \\
\text { padrões Ob- } \\
\text { jetivo e Reu- } \\
\text { so da Infor- } \\
\text { mação. }\end{array}$ & $\begin{array}{l}\text { Não. As soluções de } 4 \text { padrões } \\
\text { foram consideradas, mas há } \\
\text { muita informação na interface } \\
\text { principal e ela poderia estar } \\
\text { dividida, como descrito no } \\
\text { padrão "Passos". }\end{array}$ \\
\hline $\begin{array}{l}\text { Grupo } \\
\text { B }\end{array}$ & $\begin{array}{l}\text { Quase todos, } \\
\text { exceto o } \\
\text { padrão Obje- } \\
\text { tivo. }\end{array}$ & $\begin{array}{l}\text { Não. As soluções de } 5 \text { padrões } \\
\text { foram consideradas, mas uma } \\
\text { parte da solução do padrão "O } \\
\text { que precisa ser feito" não foi } \\
\text { considerada, pois há algumas } \\
\text { informações utilizando lingua- } \\
\text { gem técnica }\end{array}$ \\
\hline $\begin{array}{l}\text { Grupo } \\
\mathrm{C}\end{array}$ & Todos. & $\begin{array}{l}\text { Não. As soluções de } 6 \text { padrões } \\
\text { foram consideradas, mas uma } \\
\text { parte da solução do padrão } \\
\text { "Características dos passos" } \\
\text { não foi considerada, porque o } \\
\text { nome para armazenar a ativi- } \\
\text { dade é criado automaticamen- } \\
\text { te, sem a possibilidade de } \\
\text { alteração. }\end{array}$ \\
\hline $\begin{array}{l}\text { Grupo } \\
\text { D }\end{array}$ & Todos. & Sim. \\
\hline $\begin{array}{l}\text { Grupo } \\
\text { E }\end{array}$ & Todos. & Sim. \\
\hline
\end{tabular}

Tabela 6: Resultado da inspeção baseada em padrões

Após esse passo, cada grupo pôde modificar ou desenhar outras interfaces considerando o resultado da inspe- ção. Essas interfaces foram utilizadas por alunos da pedagogia e matemática no quarto passo descrito a seguir.

\subsubsection{Quarto Passo}

Duas alunas que estão no curso de pedagogia, chamadas aqui como P1 e P2, e dois de matemática, M1 e M2, utilizaram os protótipos. Cada protótipo foi utilizado por dois diferentes alunos, sendo assim, 2 alunos utilizaram 2 protótipos e os outros utilizaram 3 .

Esses alunos, que aceitaram um convite de utilizar os protótipos no horário da disciplina, responderam um questionário. Todos estão no quarto ano de seus cursos e tem familiaridade com o computador e internet e, os utilizam para ler e-mails, comprar coisas, acessar redes sociais, ouvir músicas, assistir vídeos, etc. Eles já utilizaram jogos computacionais para ensinar e, consideram que "computador é uma ferramenta educacional indispensável, pois percebem que as pessoas gostam muito"; "computador pode estimular os estudantes em participar mais das atividades educacionais" e; "computador é uma boa ferramenta, mas é necessário encontrar um sistema que está de acordo com o planejamento e intencionalidade do educador".

Após responderem os questionários, houve uma explicação geral que o objetivo seria utilizar os protótipos e que poderiam ser sinceros sobre o que é difícil, fácil, compreensível ou não para ajudar a melhorar os protótipos de forma que outras pessoas pudessem utilizá-los. Eles foram filmados enquanto estavam utilizando os protótipos e responderam dois questionários:

1 - SAM Self Assessment Manikin, que tem como objetivo registrar o sentimento dos usuários enquanto utilizam cada interface do sistema. O questionário é divido em três partes: Satisfação (S), Motivação (M) e Sentimento de Controle (SC). O SAM possui pontuação de 1 a 9, sendo 1 a pior nota [19]. A maioria das interfaces recebeu a nota máxima, porém na Tabela 7 há três dificuldades percebidas nos protótipos feitos pelos grupos A, B e $\mathrm{D}$, de acordo com os dois alunos que os utilizaram.

\begin{tabular}{l|c|c|c|c}
\hline \multicolumn{1}{c}{ Interface/Grupo } & \multicolumn{1}{c}{ Alunos } & S & M & SC \\
\hline Figura 7 / Grupo A & M1 & 8 & 9 & 9 \\
& P2 & 7 & 7 & 2 \\
\hline Similar a Figura 7 & M1 & 9 & 9 & 8 \\
/ Grupo B & P1 & 9 & 9 & 8 \\
\hline Figura 8 / Grupo D & P1 & 8 & 7 & 7 \\
& P2 & 8 & 7 & 5 \\
\hline
\end{tabular}

Tabela 7: Algumas respostas do questionário SAM

Considerando os resultados do SAM houve a avaliação das filmagens, que se iniciou por observar como foi a interação dos usuários com as interfaces que tiveram pontuações baixas. Duas das interfaces são apresentadas na Figura 8 e 9. 


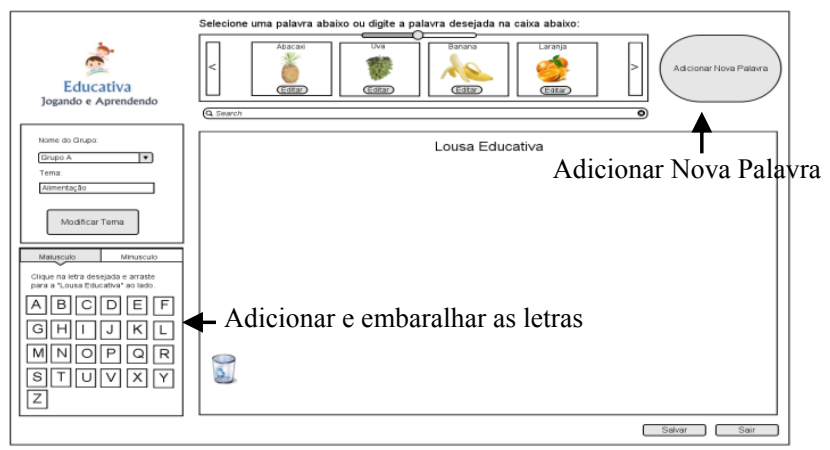

Figura 8: Interface principal do Grupo A

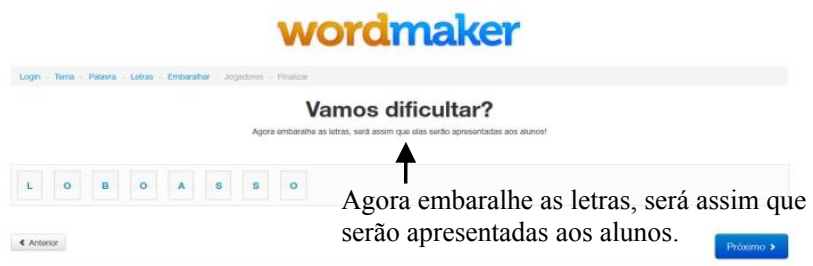

Figura 9: Interface de um passo do Grupo D

2 - Questionário, baseado na escala de Likert, foi preenchido após a utilização dos protótipos para os alunos opinarem sobre o processo de coautoria. O resultado, que se encontra na Tabela 8 , pode ter pontuação de 1 a 5.1 representa repostas menos positivas como "Muito desinteressante" e, 5 a mais positiva "Muito interessante".

\begin{tabular}{l|c|c|c|c|c}
\hline & \multicolumn{1}{c}{ Alunos } & Q1 & Q2 & Q3 & Q4 \\
\hline Grupo A & M1 & 5 & 4 & 4 & 4 \\
& P2 & 5 & 4 & 4 & 2 \\
\hline Grupo B & P1 & 5 & 4 & 4 & 4 \\
& P2 & 5 & 4 & 4 & 2 \\
\hline Grupo C & M2 & 5 & 5 & 5 & 5 \\
& P1 & 5 & 4 & 4 & 4 \\
\hline Grupo D & M1 & 5 & 5 & 4 & 4 \\
& P1 & 5 & 5 & 5 & 5 \\
\hline Grupo E & M1 & 5 & 4 & 5 & 5 \\
& M2 & 5 & 4 & 4 & 4 \\
\hline
\end{tabular}

Tabela 8: Respostas do questionário

Q1 - O sistema que permite criar atividades é:

Q2 - O seu sentimento após criar a atividade foi:

Q3 - Os passos para criar a atividade foi:

Q4 - A sequência para criar os passos foi:

Avaliando os resultados, observou-se que os alunos de ciência e engenharia da computação: (1) consideraram fácil entender os padrões e, relataram que os mesmos apoiaram no momento da discussão e elaboração dos protótipos, como ilustrado na Tabela 5. Um aluno relatou dificuldade em entender a diferença entre "Passos" e "Características dos passos", ao ler os nomes dos padrões, mas depois disse que percebeu a diferença facilmente após ler o conteúdo dos padrões. Como apenas um aluno relatou essa dificuldade, não houve alteração nos nomes. (2) conseguiram aplicar as soluções apresentadas nos padrões. Ao considerar a inspeção baseada em padrões, Tabela 6, é possível observar que a maioria das soluções foram bem aplicadas. Contudo, o padrão "Objetivo" não foi considerado pelos grupos A e B; "Reuso das informações" pelo grupo $\mathrm{A}$ e; os grupos $\mathrm{B}$ e $\mathrm{C}$ não consideraram todas as partes da solução de um dos padrões.

Embora esses grupos não tenham aplicado os padrões ou partes deles no momento do design, eles souberam utilizá-los para realizar a inspeção. Por exemplo, os grupos A e B não aplicaram o padrão "Objetivo", mas na inspeção, o grupo B identificou que A não o havia considerado e, sugeriu algumas soluções considerando a solução e os exemplos existentes no padrão. $\mathrm{O}$ que é um indício que a essência da solução está nos padrões.

Os alunos de pedagogia e matemática: (1) conseguiram utilizar os protótipos para simular a inserção das informações para criar uma atividade. (2) consideram como "Muito interessante", ou 5 pontos como ilustrado na Tabela 8 , a possibilidade de ter um sistema que permite a inserção das informações. Eles escreveram, no questionário, que a possibilidade de inserir as informações é uma boa estratégia, pois eles podem considerar o que pretendem ensinar e o perfil dos alunos; inclusive, têm a possibilidade de inserir diferentes informações para aqueles alunos que têm mais ou menos dificuldades. (3) sentiram-se "Satisfeitos", ou 4 pontos, durante o processo de coautoria.

Com relação a sequência de passos, Tabela 8 - Q4, os protótipos dos grupos A e B tiveram pontuação 2, considerada baixa. Ao avaliar o questionário SAM, Tabela 7 , foi possível identificar quais interfaces não tiveram pontuação alta e, ao analisar os vídeos percebeu-se que os protótipos não tinham uma sequência de passos linear. Por exemplo, o grupo A e de forma semelhante o grupo B dividiram em passos o processo de inserir as letras da atividade para formar uma palavra, mas no momento de inserir outras letras e embaralhá-las, o usuário tinha que voltar para a tela inicial, como ilustrado na Figura 8.

Os usuários consideraram confuso ter que voltar e sugeriram que essas opções deveriam estar nos próximos passos. Na inspeção por padrões, Tabela 6 , há no resultado a notificação ao grupo A que havia muita informação na interface principal, mas ela não foi alterada. Apesar dos outros grupos terem feito da forma adequada, foi inserido na solução do padrão "Passos" que diferentes passos são diferentes telas.

Também foi identificado um problema na mensagem que explica o que precisa ser feito em um dos passos feitos pelo grupo D, apresentado na Figura 9. Houve a explicação sobre embaralhar as letras, mas não mencionaram que isso é feito por "pegar e arrastar". Os usuários 
levaram alguns segundos para perceberem essa possibilidade. Devido a isso, foi inserida no padrão "O que precisa ser feito" a explicação sobre a necessidade de explicar "como fazer", pois antes havia informações somente sobre "o que fazer".

Outro problema identificado foi que os grupos, que não tinham considerado o padrão "Objetivo", descreveram um texto longo após a inspeção. Após o estudo de caso, os passos para formalizar padrões, Figura 5, foram refeitos como Quarto Ciclo e observou-se no passo "Analisar" que havia nos sistemas apenas uma dica sobre o objetivo na interface principal e, uma descrição mais detalhada em outra interface; por isso, houve alteração no padrão e formalização do padrão "Síntese". Os sistemas também apresentam o cadastro dos usuários para armazenar quem inseriu as informações e quem as utilizou, algo que os grupos não consideraram, por isso, houve a formalização do padrão "Usuário".

Os resultados desses ciclos são os padrões, que são apresentados parcialmente na próxima seção, com o nome dos padrões e parte da solução. A descrição completa de todos os padrões se encontra no link http://lia.dc.ufscar.br/coautoria/padroes_coautoria.pdf.

\section{Padrões de Coautoria}

Nome: Opção de coautoria - Parte da solução: Deixe visível a opção para a coautoria no início da interação, com uma frase indicativa.

Nome: Síntese - Parte da solução: Informe ao coautor a síntese do Objetivo do sistema em uma frase curta, utilizando uma linguagem simples, na primeira interface.

Nome: Objetivo - Parte da solução: Informe ao coautor o objetivo do sistema de coautoria em poucas frases, utilizando uma linguagem simples. No objetivo, descreva a regra do sistema.

Nome: Informações - Parte da solução: Considere o Objetivo do sistema para definir quais são as informações que serão inseridas pelo coautor. Dentre as informações, o cadastro do Usuário tem que constar.

Nome: Usuário - Parte da solução: Verifique quais são os dados importantes do usuário no contexto do sistema de coautoria. Solicite o cadastro desses dados para poder criar ou acessar uma instância.

Nome: Passos - Parte da solução: Crie um passo, o que significa uma tela ou interface, para a inserção de cada informação. Apenas solicite mais de uma informação, em um mesmo passo, se elas estiverem relacionadas.

Nome: Características dos passos - Parte da solução: Defina uma sequencia de passos que o coautor pode seguir, mas permita-o ir para qualquer passo em qualquer momento. O coautor deve ter a possibilidade de voltar um ou mais Passos ou ir para qualquer outro próximo passo para inserir ou editar as Informações.

Nome: O que precisa ser feito - Parte da solução: Utilize palavras que indique a ação que deve ser feita pelo coautor. Explique em uma pequena frase o que precisa ser feito em cada passo e como fazer.

Nome: Reuso do conteúdo - Parte da solução: Mostre ao coautor que há a possibilidade de acessar as Informações existentes no sistema. Escolha em que momento(s) mostrar a opção de acessar as informações existentes: 1 No início, antes de iniciar o processo de coautoria. 2 Durante o processo de coautoria.

\section{Considerações Finais}

Este artigo discute alguns conceitos existentes na literatura sobre a possibilidade de adequar sistemas computacionais de acordo com as características e necessidades dos usuários; enfatizando o conceito de coautoria que permite aos usuários, como coautores, inserirem as informações que serão exibidas pelo sistema.

Há a apresentação da metodologia de formalização de conhecimentos e experiências no design de interfaces, de sistemas que permitem coautoria, em padrões de design, com o intuito de descrever os passos e técnicas para que outros pesquisadores possam formalizar seus conhecimentos e experiências no design de sistemas educacionais e/ou nas práticas educacionais.

$\mathrm{Na}$ metodologia descrita aqui há quatro passos, Investigar, Analisar, Escrever e Validar, que foram feitos em três ciclos de forma iterativa. A formalização em ciclos iterativos permitiu que validações fossem feitas durante todo o trabalho com participantes de diferentes perfis em momentos distintos.

Os resultados dessas validações, com os referenciais teóricos, etc., pautaram as decisões para criar, alterar ou excluir o que estava feito, bem como, mostraram indícios de que os padrões de coautoria apoiam o design de sistemas de coautoria, pois os participantes compreenderam e consequentemente aplicaram as soluções de sucesso no design de protótipos de sistemas. Os grupos tiveram diferentes ideias e fizeram diferentes interfaces, mas seguindo os padrões conseguiram fazer que o processo de coautoria fosse percebido e utilizado pelos usuários, uma vez que os sistemas permitiram e auxiliaram os participantes a inserirem o conteúdo.

Como trabalho futuro, outros padrões de design, existentes na literatura que possam apoiar a coautoria, serão citados para que as pessoas possam ter acesso a outros padrões ao ler os padrões de coautoria e; outros estudos de casos serão feitos. 


\section{Agradecimentos}

Os autores agradecem a CAPES, FAPESP, Microsoft, DFAIT e BOEING.

\section{Referências}

[1] A. C. P. L. Carvalho, A. Brayner, A. Loureiro, A.L. Furtado, A. V. Staa, C. J. P. Lucena, C. S. Souza, C. M. B. Medeiros, C. L. Lucchesim, E. S. Silva, F. R. Wagner, I. Simon, J. Wainer, J. C. Maldonado, J. P. M. Oliveira; L. Ribeiro, L. Velho, M. A. Gonçalves, M M. C. C. Baranauskas, M. Matooso, N. Ziviani, P. O. A. Avaux, R. S. Torres, V. A. F. Almeida; W. M. Jr, Y. Kohayakawa. Grandes Desafios da Pesquisa em Computação no Brasil - 2006 - 2016. Relatório, 2006.

[2] A. F. Blackwell. Psychological issues in end-user programming. In: End User Development. New York: Springer, 9, páginas 9-30, 2006.

[3] A. J. Ko, R. Abraham, L. Beckwith, M. Burnett, M. Erwig, C. Scaffidi. The state of the art in end-user software engineering. In: ACM Computing Surveys (CSUR), 43, 3, Article 21, 44 p, 2011.

[4] A. Libório, E. Furtado, I. Rocha, V. Furtado. Interface design through knowledge-based systems: an approach centered on explanations from problemsolving models. In Proceedings of the 4th international workshop on Task models and diagrams (TAMODIA), ACM, New York, NY, USA, páginas 127-134, 2005.

[5] A. Lorenz, S. Werner. Tailoring UML activities to use case modeling for web application development. In Proceedings of the 2006 conference of the Center for Advanced Studies on Collaborative research (CASCON), ACM, New York, NY, USA, Article 26, páginas 1-4, 2006.

[6] A. M. Ferreira, E. N. Pereira, J. C. Anacleto, I. M. Carelli, M. A. R. Silva, A. L. Dias. A Culturally Contextualized Web based Game Environment to Support Meaningful Learning. In: International Conference on Computer Supported Education (CSEDU), Lisboa, páginas 1-6, 2009.

[7] A. Morch. Three Levels of End-User Tailoring: Customization, Integration, and Extension. In M. Kyng, \& L. Mathiassen (Eds.), Computers and Design in Context, MIT Press, Cambridge, MA, páginas 51-76, 1997.

[8] A. Sieg, B. Mobasher, R. Burke. Web search personalization with ontological user profiles. In Proceedings of the Sixteenth ACM Conference on Conference on information and Knowledge Management, Lisbon, Portugal, páginas 525-534, 2007.

[9] B. S. Da Silva, A. M. Bueno, S. D. J. Barbosa. In Análise dos mecanismos de adaptação do Mozilla Thunderbird. Departamento de Informática, PUCRio, Rio de Janeiro. Março de 2008.

[10]B. Wasson, A. I. Mørch. Identifying collaboration patterns in collaborative telelearning scenarios. In: Educational Technology \& Society. v. 3, n. 3, páginas 237-248, 2000.

[11] Berkeley Resource. Web Patterns for Building User Interfaces. Disponível em:

http://harbinger.sims.berkeley.edu/ui_designpatterns/ webpatterns $2 /$ webpatterns/home.php. Acesso em Maio de 2012.

[12] Brighton Usability Group. The Brighton Usability Patterns Collection. Disponível em: http://www.cmis.brighton.ac.uk/research/patterns/ho me.html. Acesso em Janeiro de 2013.

[13]C. Alexander, S. Ishikawa, M. Silvefstein, M. Jacobson, I. Fiksdahl-King, S. Angel. A Pattern Language: towns, buildings, construction. New York: Oxford University Press, 1171p, 1977.

[14]C. Crumlish, E. Malone. Designing Social Interfaces. Disponível em: < http://www.designingsocialinterfaces.com/patterns/ Main_Page>. Acesso em Setembro de 2012.

[15]D. C. M. Saade, H. V. O. Silva, L. F. G. Soares. Linguagem NCL versão 2.0 para Autoria Declarativa de Documentos Hipermídia. In: IX Simpósio Brasileiro de Sistemas Multimídia e Web, 17p, 2003.

[16]D. Costache, G. Kalus, M. Kuhrmann. Design and validation of feature-based process model tailoring: a sample implementation of PDE. In Proceedings of the 19th ACM SIGSOFT symposium and the 13th European conference on Foundations of software engineering (ESEC/FSE), ACM, New York, NY, USA, páginas 464-467, 2011.

[17]D. K. Van Duyne, J. A. Landay, J. I. Hong. The Design of Sites. USA: Addison Wesley, Boston MA, 816p, 2003.

[18] D. M. B. Paiva, M. G. V. Nunes, M. G. C. Pimentel. Avaliação Qualitativa de um Conjunto de Requisitos para Sistemas de Autoria Hipermídia Educacional. In: XII Simpósio Brasileiro de Informática na Educação (SBIE), Vitória - ES. páginas 355-364, 2001.

[19]E. C. S. Hayashi, V. P. A. Neris, M. C. C. Baranauskas, M. C. Martins, L. S. G. Piccolo, R. Costa. Avaliando a Qualidade Afetiva de Sistemas Computacionais Interativos no Cenário Brasileiro. In: Usabilidade, Acessibilidade, Inteligibilidade, Workshop 
no IHC, Porto Alegre. Anais do Workshop UAI, páginas 1-5, 2008.

[20]E. S. Chung, J. I. Hong, J. Lin, M. K. Prabaker, J. A. Landay, A. L. Liu. Development and Evaluation of Emerging Design Patterns for Ubiquitous Computing. In Proceedings of Designing Interactive Systems (DIS) páginas 233-242, 2004.

[21]F. A. Dorça, L. V. Lima, M. A. Fernandes, C. R. Lopes. Automatic student modeling in adaptive educational systems through probabilistic learning style combinations: a qualitative comparison between two innovative stochastic approaches. In J Braz Comput Soc, páginas 43-58, 2013.

[22]F. Montero, M. Lozano, P. González, I. Ramos. A First Approach to Design Web Sites By Using Patterns. In: First Nordic conference on Pattern Languages of Programs: VikingPLoP, Hojstrupgard, Denmark, páginas 137-158, 2002.

[23]G. Fischer. Beyond interaction: meta-design and cultures of participation. In Proceedings of the 23rd Australian Computer-Human Interaction Conference $(\mathrm{OzCHI})$, ACM, New York, USA, páginas 112-121, 2011.

[24]G. Fischer. User Modeling in Human-Computer Interaction In. User Modeling and User-Adapted Interaction (UMUAI), v. 11(1), páginas 65-86, 2001.

[25]G. Meszaros, J. Dobke. Metapatterns: A pattern language for pattern writing. In: 3rd Pattern Languages of Programming Conference, Monticello, Illinois, Páginas 1-39, 1996.

[26]H. Dieterich, U. Malinowski, T. Kuhme, M. Schneider-Hufschmidt. State of the Art in Adaptive User Interfaces. In: Adaptive User Interfaces: Principle and Practice. Amsterdam, North Holland. Elsevier Science \& Tecnology Books, páginas 13-48,1993.

[27]I. M. Pinto, S. S. C. Botelho. Ambientes Tecnológicos Lúdicos de Autoria (ATLA): criando espaços de ensino e aprendizagem, In: Revista Brasileira de Informática na Educação (RBIE), v. 20, n. 03, páginas 133-145, 2012.

[28]J. Borches. A Pattern Approach to Interaction Design. Disponível em: http://www.hcipatterns.org/patterns/borchers/patterni ndex.html. Acesso em Maio de 2012.

[29]J. Finlay. Planet: Pattern Language Network - An Overview of the Project. Disponível em: http://blip.tv/janet-finlay/planet-pattern-languagenetwork-an-overview-of-the-project-1823264. Acesso em Março de 2012.

[30]J. Löwgren. Inspirational patterns for embodied interaction. In: Nordic Design Research Conference (Nordes), Copenhagem, páginas 1-9, 2005.
[31]J. M. R. Villena, M. A. R. Silva, J. C. Anacleto. Using Culture to Help People Communication Throught Computer Games in Educational and Therapeutic Environment. In: IEEE International Conference on Systems, Man, and Cybernetics (SMC), Istanbul, páginas 1-8, 2010.

[32] J. Michael, J. J. Lorraine. Principles for a UsabilityOriented Pattern Language. In Proceedings of the Australasian Conference on Computer Human Interaction (OZCHI). IEEE Computer Society, Washington, DC, USA, páginas 132-140, 1998.

[33]J. O. Borchers. A Pattern Approach to Interaction Design. John Wiley \& Sons, Chichester, UK, 264p, 2001.

[34] J. Piaget. Psicologia e pedagogia. Rio de Janeiro: Forense, $184 \mathrm{p}, 1998$.

[35]J. Preece, Y. Rogers, H. Ssharp. Interaction design: beyond human-computer interaction. USA: John Wiley \& Sons, 519p, 2002.

[36] J. R. Eagan, J. T. Stasko. The buzz: supporting user tailorability in awareness applications. In Proceedings of the twenty-sixth annual SIGCHI conference on Human factors in computing systems (CHI). ACM, New York, USA, páginas 1729-1738, 2008.

[37] J. Rode, J. Howarth, M. A. Perez-Quinones, M. B. Rosson. An End-User Development Perspective on State-of-the-Art Web Development Tools. In: Technical Report TR-05-03, Computer Science, Virginia Tech, 32p, 2005.

[38]J. Roth. Patterns of Mobile Interaction. In: Personal and Ubiquitous Computing. v. 6, n. 4, páginas 282289, 2002.

[39]J. Tidwell. Common Ground: A Pattern Language for Human-Computer Interface Design. Disponível em:http://www.mit.edu/ jtidwell/interaction_patterns .html. Acesso em Maio de 2012.

[40] K. Beck, W. Cunningham. Using Pattern Languages for Object-Oriented Programs. In. OOPSLA'87 workshop on Specification and Design for ObjectOriented Programming. Technical Report CR-87-43, Tektronix, Inc., 1987.

[41]K. Beck. User Interface. Disponível em: http://c2.com/ppr/ui.html. Acesso em Maio de 2012.

[42]L. Findlater, J. McGrenere. Beyond performance: feature awareness in personalized interfaces. In: International Journal of Human Computer Studies, v. 68, n. 3, páginas 121-137, 2009.

[43]L. M. C. Santarosa, D. L. Conforto, L. O. Basso. Ferramentas de autoria e de colaboração: discutindo a acessibilidade e a usabilidade na perspectiva da Web 2.0. In: Revista Brasileira de Informática na Educação (RBIE), v. 21, n.01,páginas121-132, 2013. 
[44]M. A. R. Silva, J. C. Anacleto. Adaptação Contextualizada do Conteúdo da Interface de um Jogo Narrativo Educacional. In: X Simpósio de Fatores $\mathrm{Hu}$ manos em Sistemas Computacionais (IHC), Porto de Galinhas, páginas 38-47, 2011.

[45] M. Arvola. Interaction Design Patterns for Computers in Sociable Use. In Journal of Computer Application in Technology. v. 25, n. 2-3. páginas 128-139, 2006.

[46] M. C. C. Baranauskas, C. S. Souza, R. Pereira. I GranDIHC-BR - Grandes Desafios de Pesquisa em Interação Humano-Computador no Brasil. Relatório Técnico. Comissão Especial de Interação $\mathrm{Hu}-$ mano-Computador (CEIHC) da Sociedade Brasileira de Computação (SBC), 56p, 2014.

[47] M. R. Bez, A. L. Nienow, C. D. Flores. Análise de Requisitos para implementação de uma ferramenta de autoria para o desenvolvimento de objetos de aprendizagem para a área da saúde. In Revista Novas Tecnologias na Educação (RENOTE) - Educação a Distância. v. 8, n. 1, páginas 1-10, 2010.

[48] M. Schmettow, S. Niebuhr. A pattern-based usability inspection method: First empirical per-formance measures and future issues. In: Devina RamdunyEllis and Dorothy Rachovides, Proceedings of the HCI, v. 2 of People and Computers, páginas 99-102, 2007.

[49] M. Van Welie. Web Desig Patterns. Disponível em: http://www.welie.com/patterns/. Acesso em Maio de 2012.

[50] National Academy of Engineering. Advance personalized learning. Disponível em: http://www.engineeringchallenges.org/cms/8996/912 7.aspx. Acesso em Março de 2011.

[51] P. Coad, M. Mayfield. Workshop Report: Patterns. In: Addendum to the Proceedings of OOPSLA ' 92. OOPS Messenger, v. 4, n. 2, páginas 93-95, 1992.

[52] P. Coad. Object-Oriented Patterns. In: Communications of the ACM, v. 35, n. 9, páginas 152-159, 1992.

[53] P. Morville, L. Rosenfeld. Information Architecture for the World Wide Web. 3. ed. Sebastopol, CA: O’Reilly Media, 504p, 2007.

[54] R. H. Trigg, T. P. Moran, F. G. Halasz. Adaptability and tailorability in note cards. In: Proceedings of Interact' 87 , Stuttgart, North Holland, páginas 723-728, 1987.

[55] R. P. Gabriel. Patterns of Software: tales from the software community. Oxford University Press, USA, 256p, 1998.

[56] R. Slagter, M. Biemans, H. Hofte. Evolution in Use of Groupware: Facilitating Tailoring to the Extreme. Disponível
https://doc.novay.nl/dsweb/Get/Document14874/31_slagter.pdf. Acesso em Fevereiro de 2010. research/cseg/projects/pointer/patterns.html. Acesso em Maio de 2012.

[57] S. Bjork, S. Lundren, J. Holopainen. Game Design Patterns Project. Disponível em: http://www.gamedesignpatterns.org/. Acesso em Janeiro de 2013.

[58] S. L. Smith, J. N. Mosier. Guidelines for designing user interface software. In: Report MTR 9240 Mitre Corporation. Disponível em: http://hcibib.org/sam. Acesso em Janeiro de 2013.

[59] S. Laakso User Interface Design Patterns. Disponível em: http://www.cs.helsinki.fi/u/salaakso/patterns/ Acesso em Maio de 2012.

[60] S. Lukosch, T. Schümmer, T. Jarmer. There's more than just a Login: Six patterns that make connecting to a collaborative system more convenient. In EuroPlop, páginas 1-26, 2007.

[61]S. Marathe, S. S. Sundar. What drives customization?: control or identity?. In: Proceedings of the annual conference on Human factors in computing systems (CHI), ACM, New York, NY, USA, páginas 781-790, 2011.

[62] School of Computing and Communications. Patterns of Interaction: a Pattern Language for CSCW. Disponível em:http://www.comp.lancs.ac.uk/computing/

[63]T. Clear, D. Kassabova. Motivational Patterns in Virtual Team Collaboration. Research and Practice in Information Technology. Australasian Computing Education Conference. Newcastle, Australia, v.2, 8p, 2005.

[64] T. Coram, J. Lee. Experiences - A Pattern Language for User Interface Design. Disponível em: http://www.maplefish.com/todd/papers/Experiences. html. Acesso em Maio de 2012.

[65] T. S. Saponas, M. K. Prabaker, G. D. Abowd, J. A. Landay. The impact of pre-patterns on the design of digital home applications. In Proceedings of the 6th conference on Designing Interactive systems (DIS), ACM, New York, NY, USA, páginas 189-198, 2006.

[66] V. P. A. Neris, M. C. C. Baranauskas. Designing tailorable software systems with the users participation, 09/2012. In Journal of the Brazilian Computer Society, Vol. 18, Rio de Janeiro, RJ, Brasil, páginas 213-227, 2012.

[67] W3C. Authoring Tool, Social Media. Disponível em: http://www.w3.org/standards/agents/authoring. Acesso em Fevereiro de 2013.

[68] Yahoo!. Design Pattern Library. Disponível em: http://developer.yahoo.com/ypatterns/. Acesso em Maio de 2012. 